\title{
Annexin V homodimer protects against ischemia reperfusion-induced acute lung injury in lung transplantation
}

\author{
Kohei Hashimoto, MD, ${ }^{a}$ Hyunhee Kim, MSc, ${ }^{a}$ Hisashi Oishi, MD, PhD, ${ }^{a}$ Manyin Chen, MD, \\ Ilker Iskender, MD, ${ }^{\mathrm{a}}$ Jin Sakamoto, MD, ${ }^{\mathrm{a}}$ Akihiro Ohsumi, MD, ${ }^{\mathrm{a}}$ Zehong Guan, MSc, ${ }^{\mathrm{a}}$ \\ David Hwang, MD, PhD, ${ }^{\mathrm{b}}$ Thomas K. Waddell, MD, PhD, ${ }^{\mathrm{a}}$ Marcelo Cypel, MD, MSc, \\ Mingyao Liu, MD, MSc, ${ }^{a}$ and Shaf Keshavjee, MD, $\mathrm{MSc}^{\mathrm{a}}$
}

\begin{abstract}
Objective: We hypothesized that administration of a homodimer of recombinant annexin V, diannexin, could shield phosphatidylserine on the endothelium, and inhibit leukocyte and platelet adhesion, thereby potentially reducing ischemia reperfusion injury (IRI) in lung transplantation. This hypothesis was tested using a rat syngeneic single left-lung transplant model.
\end{abstract}

Methods: Rats were randomly assigned to receive diannexin (DN group; $\mathrm{n}=10$ ) or normal saline (control group; $\mathrm{n}=10)$. Diannexin $(1000 \mu \mathrm{g} / \mathrm{kg}$ ) was administered to the donor lung in the pulmonary flush solution, and to the recipient intravenously, 5 minutes after initiation of reperfusion. Grafts were reperfused for 2 hours.

Results: The transplanted grafts in the $\mathrm{DN}$ group performed significantly better in gas exchange with higher partial pressure of oxygen (control group: $179 \pm 121$ vs DN group: $330 \pm 54 \mathrm{~mm} \mathrm{Hg} ; P=.007)$ and lower partial pressure of carbon dioxide (control: $55.1 \pm 26$ vs DN: $34.2 \pm 11 \mathrm{~mm} \mathrm{Hg} ; P=.04$ ), as well as lower peak airway pressure (control: $20.5 \pm 8.5 \mathrm{vs} \mathrm{DN}: 12.0 \pm 7.9 \mathrm{~cm} \mathrm{H}_{2} \mathrm{O} ; P=.035$ ) after 2 hours of reperfusion. Wet-to-dry lung weight ratio $(P=.054)$, and alveolar fibrin deposition score $(P=.04)$, were reduced in the DN group. Caspase-cleaved cytokeratin 18 in plasma (a marker of epithelial apoptosis) was significantly reduced in the DN group $(P=.013)$. Furthermore, gene-expression levels of proinflammatory cytokines in the transplanted graft, including interleukin-6 $(P=.04)$ and macrophage inflammatory protein $2(P=.03)$ were significantly decreased in the $\mathrm{DN}$ group.

Conclusions: A homodimer of recombinant annexin V reduced ischemia reperfusion injury in a lung transplant animal model, by reducing cell death and tissue inflammation. (J Thorac Cardiovasc Surg 2016;151:861-9)

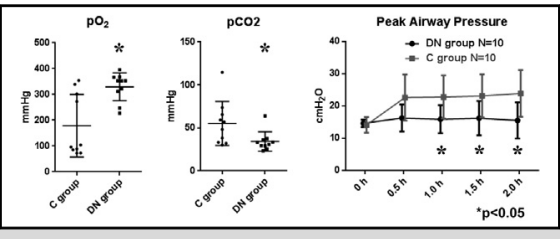

Functional improvement of the rat transplanted lung by diannexin treatment.

\section{Central Message}

Diannexin reduces ischemia reperfusion injury in a rat lung transplant model by reducing cell death, inflammation, and alveolar injury.

\section{Perspective}

Primary graft dysfunction is the clinical manifestation of ischemia reperfusion injury after lung transplantation, and it limits successful outcomes. We have demonstrated that diannexin reduces ischemia reperfusion injury in a rat lung transplant model by reducing cell death, inflammation, and alveolar injury. This novel therapy potentially can be used to prevent primary graft dysfunction.

See Editorial Commentary page 870.

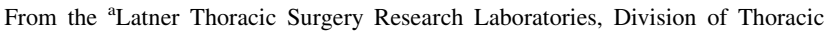
Surgery, University Health Network, University of Toronto; and ${ }^{\mathrm{b}}$ Department of Laboratory Medicine and Pathobiology, University of Toronto, Toronto, Ontario, Canada.

This work was supported by the Canadian Institutes of Health Research (OOP\#312227, Ottawa, Ontario, Canada). K.H. is supported by a grant from the Mitsukoshi Health and Welfare Foundation, Tokyo, Japan, and by an Ishidsu Shun Memorial Scholarship (Tokyo, Japan).

Read at the 95th Annual Meeting of The American Association for Thoracic Surgery, Seattle, Washington, April 25-29, 2015.

Received for publication June 11, 2015; revisions received Oct 1, 2015; accepted for publication Oct 18, 2015; available ahead of print Dec 23, 2015.

Address for reprints: Shaf Keshavjee, MD, MSc, Division of Thoracic Surgery,

Toronto General Hospital, University Health Network, University of Toronto,

190 Elizabeth St, RFE 1-408, Toronto, Ontario M5G 2C4, Canada (E-mail:

Shaf.Keshavjee@uhn.ca).

$0022-5223 / \$ 36.00$

Copyright (c) 2016 by The American Association for Thoracic Surgery

http://dx.doi.org/10.1016/j.jtcvs.2015.10.112
Primary graft dysfunction (PGD) is the clinical manifestation of ischemia reperfusion injury (IRI) in the acute phase after lung transplantation, characterized by significant deterioration of gas exchange and chest radiograph infiltration. ${ }^{1}$ PGD is the leading cause of early morbidity and mortality after lung transplantation. ${ }^{2}$ In addition, PGD is associated with decreased long-term survival, ${ }^{2}$ impaired physiologic function $^{3}$ and the development of chronic lung allograft dysfunction. ${ }^{4}$ No therapies have been established to treat this condition.

In the initial stage in the pathogenesis of IRI, phosphatidylserine translocation in the anoxic or early apoptotic endothelium stimulates leukocyte and activated platelet attachment, resulting in impaired blood flow and the 


\section{Abbreviations and Acronyms \\ CK18-M30 = caspase-cleaved cytokeratin 18 \\ $\mathrm{DN}$ group $=$ Diannexin group \\ IRI $=$ ischemia reperfusion injury \\ PAI-1 = plasminogen activator inhibitor-1 \\ PGD $=$ primary graft dysfunction \\ mRNA $=$ messenger ribonucleic acid \\ TUNEL $=$ terminal deoxynucleotidyl transferase dUTP nick end labeling}

development of a local proinflammatory and procoagulant microenvironment. ${ }^{5,6}$ The multidrug resistance gene 1 product, $\mathrm{P}$ (permeability)-glycoprotein, transports phosphatidylserine to the outer leaflet of the plasma membrane bilayer. ${ }^{7}$ Mice deficient in P-glycoprotein have been found to be protected against IRI in the kidney. ${ }^{8}$

Diannexin, a homodimer of recombinant human annexin $\mathrm{V}$, is designed to shield phosphatidylserine, to prevent cell adhesion, improve blood flow and diminish subsequent tissue injury. ${ }^{9}$ In fact, in vivo microscopy in a liver ischemia reperfusion model showed that administration of this drug leads to significant improvement in microcirculatory flow and to reduced tissue injury, ${ }^{10}$ and it has been proven to diminish tissue injury in several other IRI models. These include models of heart, using coronary artery occlusion; muscle flap; liver transplant; kidney; and islet transplant. ${ }^{11-15}$ The theoretical benefit of this agent, compared with other agents, may be that it targets early IRI, rather than individual downstream pathways. However, the drug has not been examined in the context of lung IRI.

The disruption of the microcirculation with extremely reduced red blood cell velocities in the transplanted lung has been well described, with use of intravital microscopy in a pig model. ${ }^{16}$ Additionally, significant numbers of apoptotic cells have been documented in human and animal transplanted lungs in the early reperfusion phase. ${ }^{17-19}$ Apoptotic cells externalize phosphatidylserine on the membrane ${ }^{20}$ and therefore can be targeted by this treatment. We hypothesized that the shielding of phosphatidylserine by the annexin $\mathrm{V}$ homodimer can be protective against IRI in lung transplantation.

\section{METHODS}

A rat syngeneic orthotopic single left-lung transplant model was used. Male, inbred Lewis rats (250-300 g; Charles River Laboratories, Inc, Senneville, Quebec, Canada) were used. The rat lung transplant technique has been described. ${ }^{18,19}$ The investigational protocol was approved by the Toronto General Hospital Research Institute/University Health Network Animal Care committees. All animals received humane care in compliance with guidelines from the Canadian Council on Animal Care.

\section{Experimental Design}

The recombinant homodimer of human annexin V (Diannexin/ASP8597) was gifted by Astellas Pharma, Inc (Tokyo, Japan). This agent is $73 \mathrm{kDa}$ in size and has a half-life of 7 hours in rat. ${ }^{9}$ Rats were allocated to 1 of 2 study groups ( $\mathrm{n}=10$ per group) in a blinded and randomized fashion. In the control group, normal saline (vehicle control) was administered to the donor lung and the recipient. In the Diannexin group (DN group), the drug was administered to both the donor lung and the recipient.

Donor rats were anesthetized, tracheally intubated, and ventilated. Heparin sodium (300 Units) (Heparin Sodium Injection USP; Sandoz Canada Inc, Boucherville, Quebec, Canada) was administered through the inferior vena cava. The heart lung block was retrieved after being flushed with $20 \mathrm{~mL}$ of pulmonary preservation solution (Perfadex; Vitrolife, Uppsala, Sweden) containing the following: $6 \mu \mathrm{L}$ of $3.3 \mathrm{mmol} / \mathrm{mL}$ tromethamine injection (THAM, Vitrolife), $1.2 \mu \mathrm{g}$ of calcium chloride (Omega Laboratories Ltd, Montreal, Quebec, Canada), $10 \mu \mathrm{g}$ of prostaglandin $\mathrm{E}_{1}$ (Pfizer Canada, Inc, Kirkland, Quebec, Canada), and Diannexin $(1000 \mu \mathrm{g} / \mathrm{kg})$ or vehicle control. The inflated lung was preserved in $40 \mathrm{~mL}$ of Perfadex, comprised of the same components as the flushing solution, but without diannexin, for 12 hours at $4^{\circ} \mathrm{C}$.

For the recipient rats, the right jugular vein was cannulated for fluid injection. Recipients were ventilated with $100 \%$ oxygen and isoflurane at a tidal volume of $10 \mathrm{~mL} / \mathrm{kg}$ throughout the procedure. Methylprednisolone sodium succinate (5 mg; SOLU-MEDROL; Pfizer Canada, Inc) was systemically administered. A left thoracotomy was performed, and the left native lung was dissected free. The donor left lung graft was anastomosed using a cuff technique. ${ }^{21}$ Implantation time or warm ischemic time was approximately 20 minutes. Five minutes after reperfusion, $1000 \mu \mathrm{g} / \mathrm{kg}$ of diannexin or normal saline was administered via a jugular vein catheter.

A separate ventilation technique ${ }^{22}$ was used, wherein the native right lung and the transplanted left lung were independently ventilated with tidal volumes of $6 \mathrm{~mL} / \mathrm{kg}$ (Harvard Apparatus Canada, Saint-Laurent, Quebec, Canada) and $4 \mathrm{~mL} / \mathrm{kg}$ (flexiVent FX Module 3, SCIREQ, Montreal, Quebec, Canada), respectively. This technique facilitates the accurate measurement of isolated physiologic function in the transplanted graft. Blood gas analysis was performed via pulmonary vein of the graft at 2 hours after reperfusion (Figure 1).

\section{Sample Processing}

Blood was sampled in heparinized syringes, and centrifuged for 5 minutes at $6000 \mathrm{rpm}$ to generate plasma. Plasma samples were snap-frozen and stored at $-80^{\circ} \mathrm{C}$. The lung graft samples were separated into 3 components: The upper portion was used for wet-to-dry lung weight ratio analysis; the middle portion was assessed histologically; and the lowest portion was snap-frozen immediately, to be used for mRNA (messenger ribonucleic acid) and protein studies. For wet-to-dry ratio analysis, lung tissue was weighed and placed in an oven at $80^{\circ} \mathrm{C}$ for 72 hours. The portion was reweighed, and the ratio of the lung weight from before and after drying was calculated.

\section{Histologic Graft Assessment and Acute Lung Injury Score}

Lung samples were fixed in $10 \%$ formalin and embedded in paraffin, sectioned (4- $\mu \mathrm{m}$ thickness), and stained with standard hematoxylin and eosin or Martius scarlet blue. The sections stained with hematoxylin and eosin were assessed and scored by a pulmonary pathologist in a blinded fashion. The scoring criteria included: alveolar hemorrhage (presence of red blood cells in air space); vascular congestion ( $>75 \%$ of alveolar septum occupied with red blood cells); alveolar fibrin; and leukocyte infiltration. These criteria were graded on a 4-level scale of abnormalities: normal appearance $(0 \%)$; mild $(<10 \%)$; moderate $(10 \%-50 \%)$; and severe $(>50 \%)$, scored from 0 to 3 , respectively.

\section{Immunofluorescence Staining}

Diannexin localization. Deparaffinized slides were processed with antigen retrieval in boiling $0.01 \mathrm{M}$ citrate buffer $(\mathrm{pH}=6)$ for 20 minutes. 


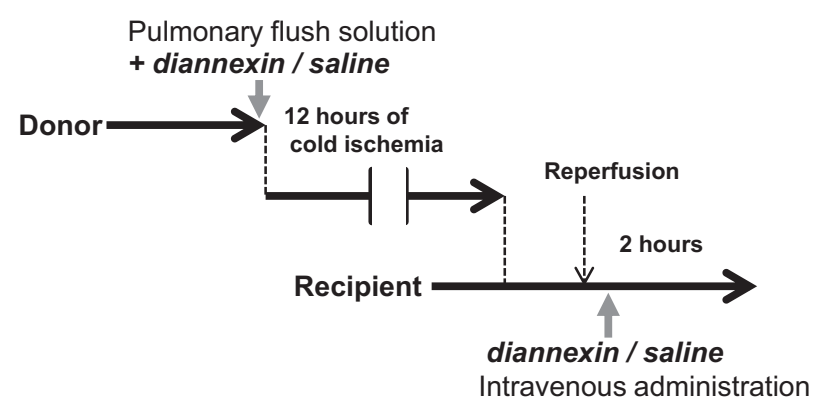

FIGURE 1. Diagram of study protocol. Diannexin or normal saline was added to donor pulmonary flushing solution, and administrated to recipient 5 minutes after reperfusion.

The sections were blocked for 1 hour, followed by incubation overnight at $4^{\circ} \mathrm{C}$, with rabbit anti-CD31 (ab28364; Abcam, Cambridge, United Kingdom) at a 1:300 dilution, and mouse antihuman annexin $\mathrm{V}$ (ab54775; Abcam) at a 1:500 dilution. Goat antirabbit IgG-Alexa 555 (A21429; Molecular Probes, Inc, Eugene, Ore) and goat antimouse IgGAlexa 488 (A11011; Molecular Probes, Inc) were used as a secondary antibody.

TUNEL staining. Terminal deoxynucleotidyl transferase dUTP nick end labeling (TUNEL) staining was performed using the In Situ Cell Death Detection Kit, TMR red (Roche Diagnostics, Indianapolis, Ind) according to manufacturer instructions. Slides were counterstained with 4', 6-diamidino-2-phenylindole and observed under fluorescent microscopy.

Real-time RT-PCR. Total RNA was extracted using the RNeasy Mini Kit (Canada QIAGEN Inc, Mississauga, Ontario, Canada) and converted to complementary DNA (deoxyribonucleic acid), using Transcriptor First Strand cDNA Synthesis Kit (Roche Diagnostics, Indianapolis, Ind). These were amplified using SYBR Green I Master mix and quantified using a LightCycler 480 (both from Roche Diagnostics). The RNA levels of interleukin-6, macrophage inflammatory protein 2 , growth-regulated oncogene, interleukin-1 $\beta$, plasminogen activator inhibitor-1 (PAI-1), and actin were quantified.

Plasma protein measurement. The plasma concentrations of circulating apoptosis marker, ${ }^{23,24}$ caspase-cleaved cytokeratin 18 (Rat Cytokeratin 18M30, MBS730477; MyBioSource, San Diego, Calif), PAI-1 IRPAIKT; (Innovative Research, Inc, Novi, Mich), and thrombin (Elabscience Biotechnology Co., Ltd, Beijing, People's Republic of China) were measured using an enzyme-linked immunosorbent assay, according to manufacturer instructions.

Measurement of protein level in lung samples. Lung tissue was lysed in $0.7 \mathrm{~mL}$ of tissue lysis buffer (10 mM 4-(2-hydroxyethyl)1-piperazineethanesulfonic acid (HEPES), $10 \mathrm{mM}$ potassium chloride, $0.1 \mathrm{mM}$ ethylene glycol tetra-acetic acid, $0.6 \%$ Nonidet P-40) on TissueLyzer (QIAGEN Inc, Toronto, Ontario, Canada), followed by centrifugation at $12,000 \mathrm{rpm}$ and $4^{\circ} \mathrm{C}$. The supernatant was collected, and protein concentration was measured using the Bradford protein assay reagent (BioRad, Hercules, Calif).

ELISA. The enzyme-linked immunosorbent assay of interleukin-6 (KRC0061; Life Technologies, Carlsbad, Calif), macrophage inflammatory protein 2 (CSB-E07419r; Cusabio Biotech Co., Ltd, Wuhan, People's Republic of China), growth-regulated oncogene (GRO) (ADI-900-074; Enzo Life Science, Inc, Farmingdale, NY) and interleukin- $1 \beta$ (SEA563RA; USCN Life Science Inc. Houston, Tex) and thrombin/antithrombin complex (EKU07627; Biomatik, Cambridge, Ontario, Canada) were performed according to manufacturer instructions.

Western blots. Western blotting was performed as described elsewhere. ${ }^{25}$ Antibodies against caspase 3 (sc-7148), intercellular adhesion

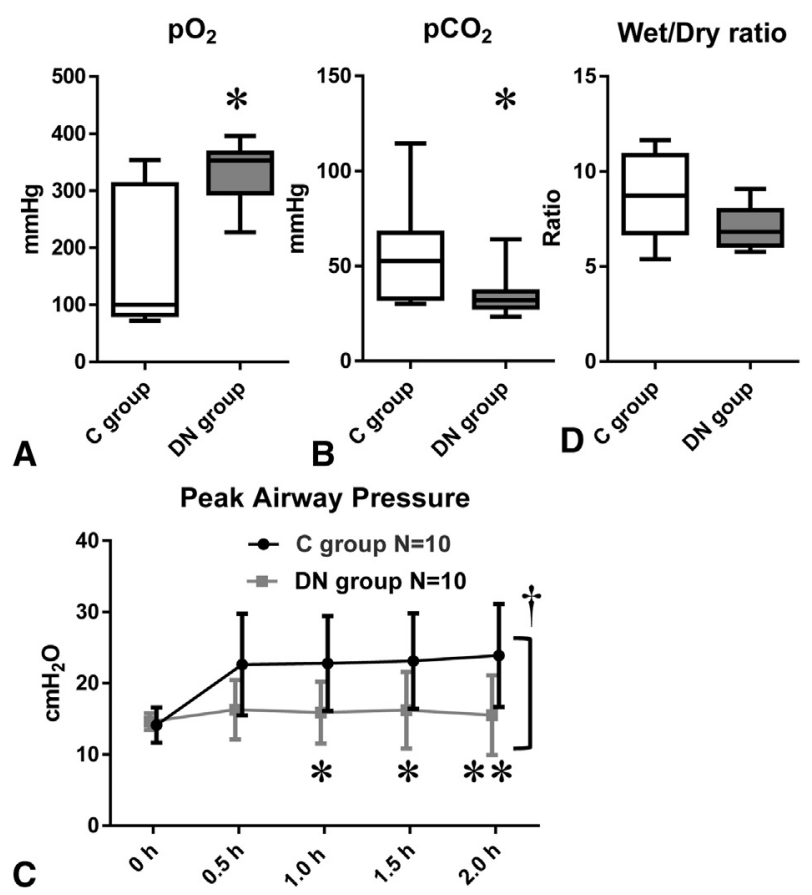

FIGURE 2. A homodimer of recombinant annexin $\mathrm{V}$ improves physiologic function of the transplanted graft. A, Oxygenation in the pulmonary venous blood was significantly improved $(* P=.004)$. B, Gas exchange was better in the DN group $(* P=.04)$. C, Peak airway pressure was decreased in the treatment group. $(\dagger P=.0001$ in 2-way repeated analysis of variance; $* * P<.01$ and $* P<.05$ in a post hoc Bonferroni test. $\mathrm{D}$, The wet/dry ratio was lower in the $\mathrm{DN}$ group $(\mathrm{P}=.054) . \mathrm{pO}$, Partial pressure of oxygen; $\mathrm{pCO}_{2}$, partial pressure of carbon dioxide; $C$, control; $D N$, diannexin.

molecule 1 (sc-107; both from Santa Cruz Biotechnology, Inc, Dallas, Tex), poly (ADP [adenosine diphosphate]-ribose) polymerase-1 (8541; Cell Signaling Technology, Inc, Danvers, Mass), and actin (ab8226; Abcam) were used.

\section{Statistical Analysis}

All data are expressed as mean $\pm \mathrm{SD}$. All graphs are expressed by box-and-whisker (minimum to maximum) plots. The Mann-Whitney $U$ test or the unpaired $t$ test was used to determine statistical significance, as appropriate. For peak airway pressures, a 2- way repeated-measures analysis of variance with a post hoc Bonferroni test was performed at each time point. Statistics were calculated with GraphPad Prism 6 (GraphPad Software Inc, La Jolla, Calif).

\section{RESULTS}

\section{Diannexin Improved Function of the Transplanted Graft}

The transplanted grafts in the DN group had a superior gas exchange with a significantly higher $\mathrm{pO}_{2}$ (partial pressure of oxygen) (control group: $179 \pm 121$ vs DN group: $330 \pm 54 \mathrm{~mm} \mathrm{Hg} ; P=.007$ ) (Figure 2, A) and lower $\mathrm{pCO}_{2}$ (partial pressure of carbon dioxide) (control group: $55.1 \pm 26$ vs DN group: $34.2 \pm 11 \mathrm{~mm} \mathrm{Hg}$; $P=.04$ ) (Figure $2, B$ ). The peak airway pressures in the 


\section{Transplanted lung Native right lung}

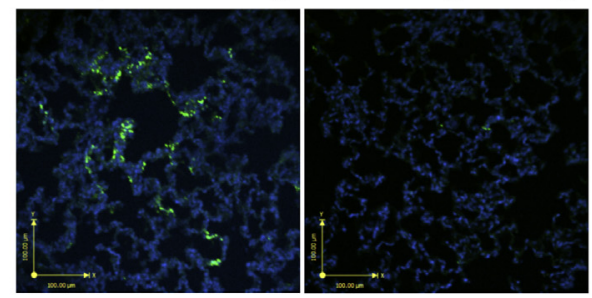

Alveolar area of transplanted graft
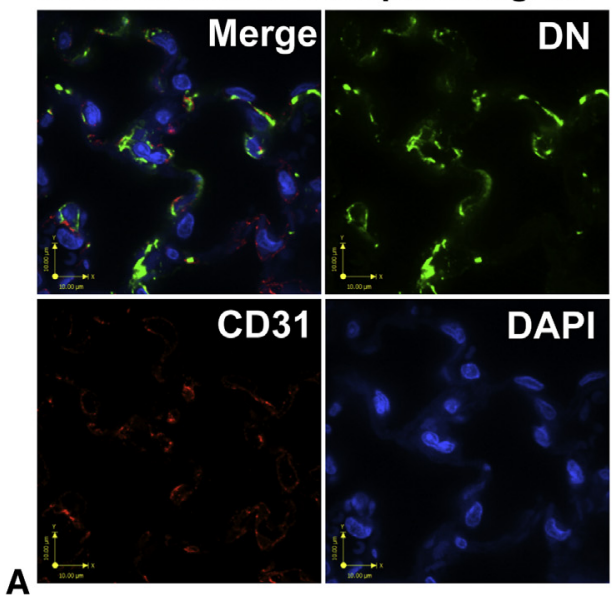

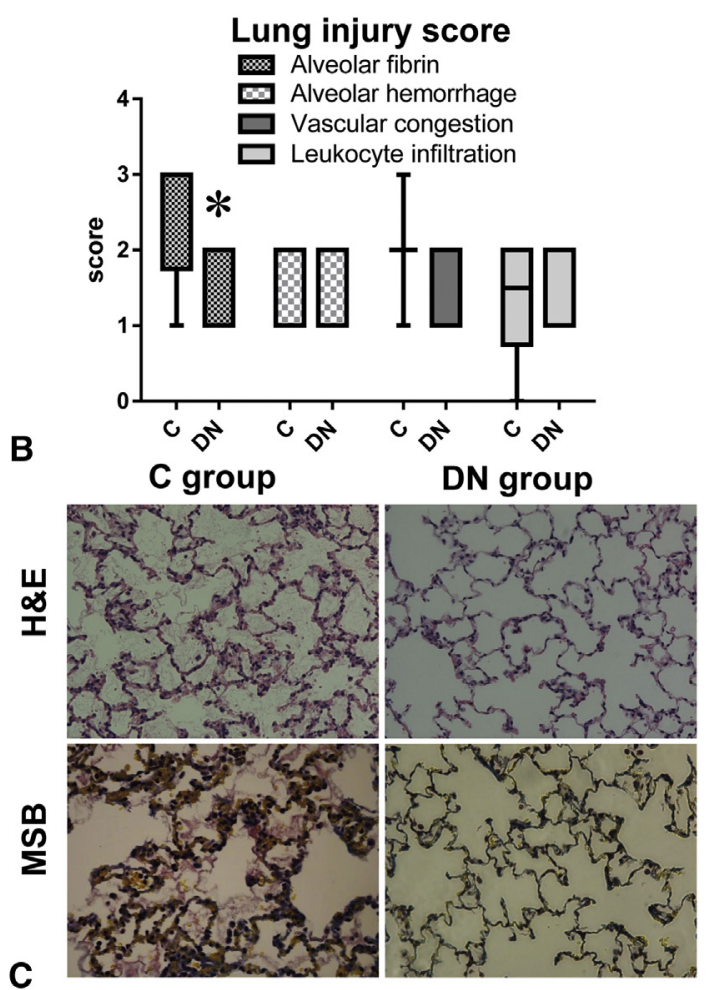

FIGURE 3. Localization of the homodimer of recombinant annexin $V$ in the lung graft, and histologic assessment of lung injury. A, Representative images of the transplanted and native right lungs (in the same animal in the DN group) at 2 hours after reperfusion, stained with DN (green). The homodimer was localized primarily in the transplanted graft and rarely in the native right lung. In the alveolar area of the transplanted graft, DN staining was present along alveolar walls, mainly adjacent to the endothelium of alveolar capillaries (red $=\mathrm{CD} 31$ positive); blue $=$ DAPI. B, Alveolar fibrin deposition was significantly improved $(* P=.04$ ). C, Representative images (x 200) from the $\mathrm{C}$ and DN groups, using H\&E and MSB staining, demonstrating intra-alveolar fibrinous exudates (pink staining in MSB stain) in the C-group, which are much less apparent in the DN group. DN, Diannexin; DAPI, $4^{\prime}$, 6-diamidino-2-phenylindole; $C$, control; $H \& E$, hematoxylin and eosin; $M S B$, Martius scarlet blue.

DN group transplanted grafts were superior $(P=.0001 ; 2-$ way repeated analysis of variance) (control group: $20.5 \pm 8.5$ vs DN group: $12.0 \pm 7.9 \mathrm{~cm} \mathrm{H}_{2} \mathrm{O}$ at 2 hours of reperfusion; $P=.009$ ). A statistically significant difference between the control and DN groups was observed starting at 1 hour after reperfusion (Figure 2,C). The wet-to-dry ratio of the retrieved graft after 2 hours of reperfusion tended to be lower in the DN group (control group: $8.7 \pm 2.2$ vs $\mathrm{DN}$ group: $7.1 \pm 1.1 ; P=.054)$ (Figure 2, D).

\section{Diannexin was Found in Reperfused Grafts}

An assessment for positivity for the drug, using an antihuman annexin $\mathrm{V}$ antibody, showed that it was present in the transplanted grafts of the DN group, but rarely in the native right lung. In the donor right lung, after 12 hours of cold ischemia, the drug was found mainly in the larger vessels (not shown). As a negative control, positivity was not found in the reperfused graft of the control group (not shown). The drug was colocalized mainly adjacent to CD31-positive endothelial cells in the alveolar area of the transplanted graft (Figure 3, A).

\section{Reduced Alveolar Fibrin Deposition in the Diannexin Group}

In histologic assessment of transplanted grafts, we found the alveolar fibrin score to be significantly improved in the DN group (control group: median 2 [interquartile range: 2, 3] vs DN group: median 1 [interquartile range: $1,1.75$ ]; $P=.04$ ) (Figure 3, B), with much less intra-alveolar fibrin apparent in the DN group than in the control group, in sections stained with hematoxylin and eosin and those stained with Martius scarlet blue (Figure 3, C).

\section{Cell Death was Suppressed by Diannexin}

The frequency of TUNEL-positive cells in the transplanted graft was lower in the DN group, but this difference was not statistically significant (control group: $122 \pm 30$ vs DN group: $59.3 \pm 25$ cells per high-power field; $P=.15$ ) (Figure 4, A). CK18-M30 is an enzymatic product of cytokeratin 18 cleaved by caspases $(3,6$, and 9$)$, and released by apoptotic epithelial cells. ${ }^{23,24}$ In plasma, CK18-M30 was significantly decreased in the DN group (control group: $2.2 \pm 0.5$ vs DN group: $1.6 \pm 0.5 \mathrm{ng} / \mathrm{mL} ; P=.013$ ) (Figure $4, B$ ). In western blots of the transplanted grafts 
TUNEL positive cells

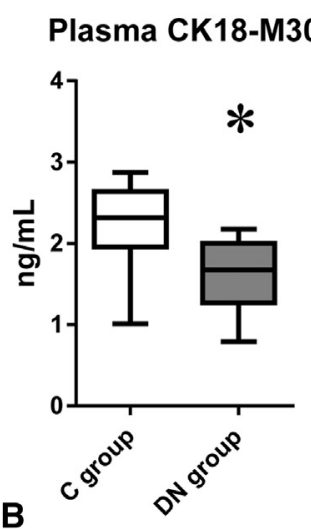

A

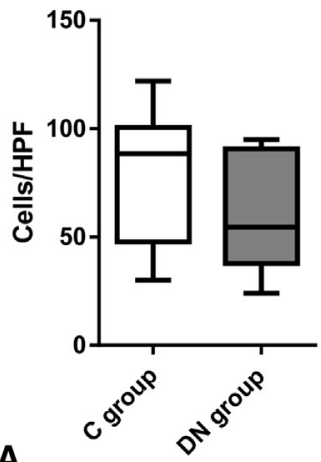

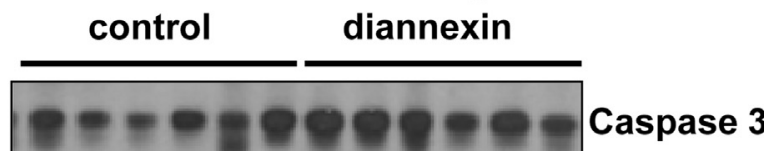
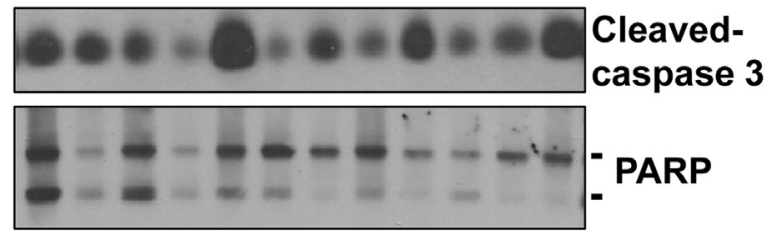

Caspase 3
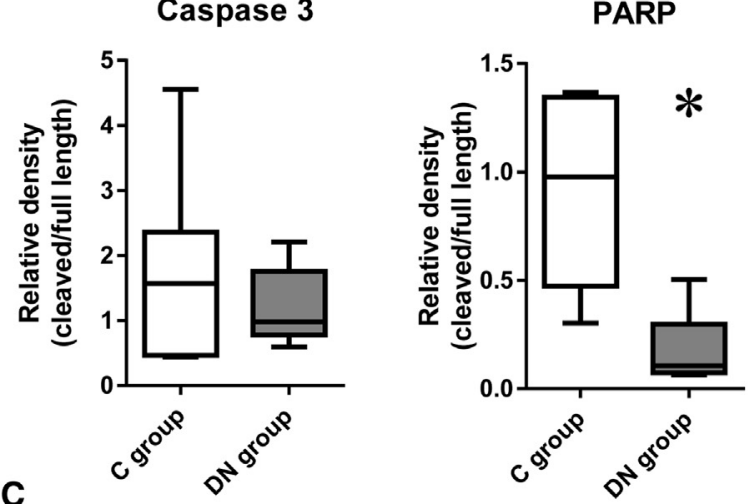

FIGURE 4. Analyses of cell death in plasma and graft. A, TUNELpositive cells were lower in the $\mathrm{DN}$ group $(P=.15)$. B, Plasma CK18-M30 was significantly higher in the control group, compared with the DN group $(* P=.013)$. C, Western blot analysis in the graft of expression of proapoptotic proteins. The expression of PARP and caspase 3 were probed using respective anti-rat antibodies. The relative density of cleaved/full-length molecules showed that the DN group had a significantly lower ratio in PARP $(* P=.01)$, and lower caspase $3(P=.89)$. In the picture of PARP, the upper blots represent full-length PARP; lower blots represent cleaved PARP. TUNEL, Terminal deoxynucleotidyl transferase dUTP nick end labeling; CK18-M30, caspase-cleaved cytokeratin 18; $H P F$, high-powered field; $C$, control; $D N$, Diannexin; PARP, poly (ADP [adenosine diphosphate]-ribose) polymerase-1.

( $\mathrm{n}=6$ each), the ratio of cleaved caspase 3 to full caspase 3 was not significantly different between the control and DN groups $(P=.89)$; however, the ratio of cleaved to full-length poly (ADP-ribose) polymerase-1 was significantly lower in the DN group $(P=.003)$ (Figure $4, C)$.

\section{Intragraft Proinflammatory Cytokine Expression was Suppressed in the Diannexin Group}

Assessment of key inflammatory cytokines in the transplanted graft after 2 hours of reperfusion is summarized in Figure 4. The DN group showed significantly lower mRNA expression of multiple cytokines, including interleukin-6 $(P=.012)$ and macrophage inflammatory protein 2 (rat homologue of human interleukin-8; $P=.03)$. Similarly, the mRNA expression levels of growth-regulated oncogene $(P=.14)$ and interleukin-1 $\beta$ $(P=.21)$ were lower, although these differences were not statistically significant (Figure 5, A).

The enzyme-linked immunosorbent assay analysis demonstrated that protein levels of interleukin-6 were significantly lower in the DN group $(P=.0015)$, but protein-level expression of macrophage inflammatory protein 2 , growth-regulated oncogene, and interleukin- $1 \beta$ were not statistically different between groups (Figure 5, $B)$. Western blot analysis showed that expression of the proinflammatory intercellular adhesion molecule 1 was decreased in the DN group $(P=.01)$ (Figure $5, C)$.

\section{Fibrinolysis was Reduced in the Diannexin-Treated Group}

To assess the impact of the drug on fibrinolysis and coagulation, the mRNA and protein levels of key molecules in these pathways were measured (Figure $6, A$ ). The mRNA level of PAI-1 in the graft tended to be lower in the DN group $(P=.054)$, whereas the protein level of PAI-1 in the plasma was significantly lower in the DN group $(P=.009)$ (Figure 6, A). The thrombin-antithrombin complex levels in the graft and plasma thrombin levels were similar across study groups and were not significantly different (Figure 6, $B$ ).

\section{DISCUSSION}

In this study, we found that diannexin successfully protected against acute lung injury related to IRI, as evidenced by improved gas exchange and lower peak airway pressure of the transplanted graft, as well as decreased alveolar fibrin deposition. In addition, we found that changes related to inflammation, cell death, and fibrinolysis were improved by treatment with this agent. These findings suggest that using this drug to shield phosphatidylserine may be of value as a clinical therapeutic strategy in the early phase of reperfusion in lung transplantation. Given that primary graft dysfunction (PGD) is one of the most challenging complications in lung transplantation and is associated with significant morbidity and mortality, the positive effects of this agent on ameliorating PGD may have a substantial impact on the field. 
IL-6

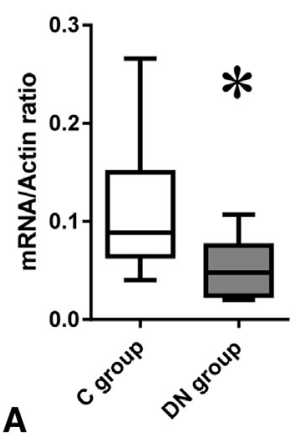

IL-6 in the graft

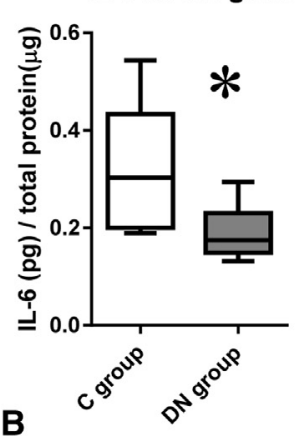

B

Western blots in the graft

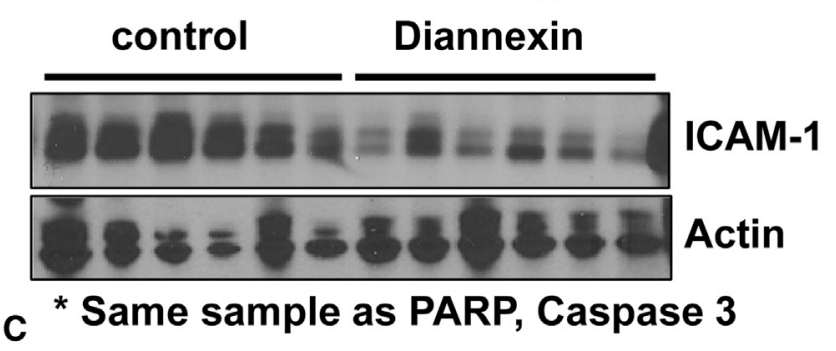

MIP-2

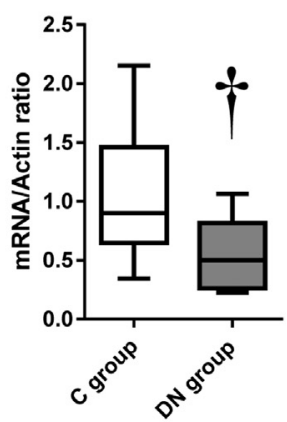

MIP-2 in the graft

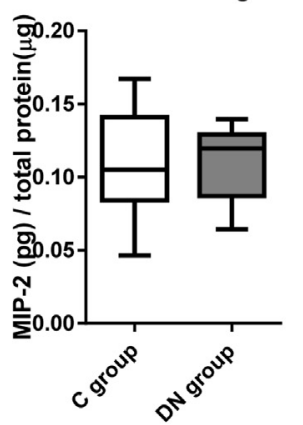

GRO

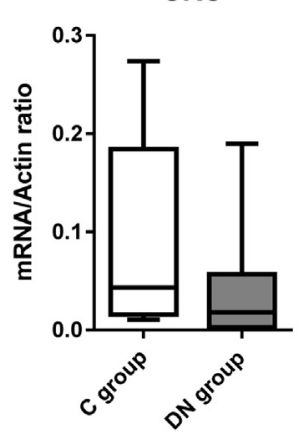

GRO in the graft

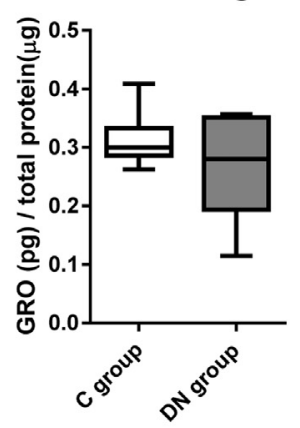

IL-1 $\beta$

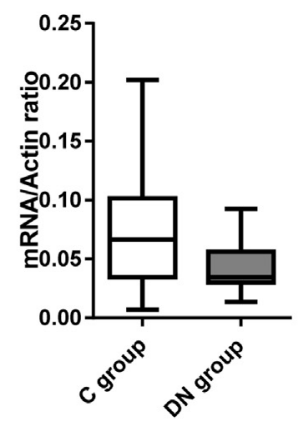

IL-1 $\beta$ in the graft

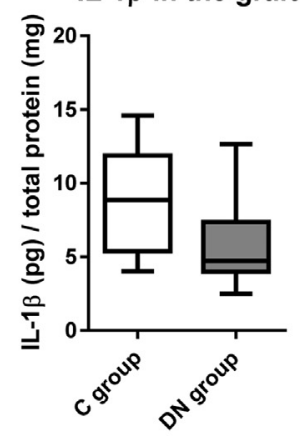

ICAM-1

FIGURE 5. Intragraft proinflammatory cytokine and adhesion molecule expression patterns. A, Reverse transcriptase-polymerase chain reaction analysis showed that the homodimer of annexin $\mathrm{V}$ significantly decreased the expression of mRNA coding for IL-6 (*P $=.012)$ and MIP-2 (†P $=.03)$, but not significantly for GRO $(P=.14)$ or IL-1 $\beta(P=.21)$. B, An enzyme-linked immunosorbent assay showed that the homodimer significantly decreased the protein level of IL-6 $(* P=.001)$ but not MIP-2 $(P=.84)$, GRO $(P=.31)$ or IL-1 $\beta(P=.07)$. C, Western blot analysis for ICAM-1 (n $=6$ each group) showed that the homodimer ameliorated the expression of ICAM-1 in the graft $(* P=.01)$. Samples analyzed for the Western blots are the same as for PARP and caspase-3 analysis. IL, Interleukin; $M I P$, macrophage inflammatory protein; $G R O$, growth-regulated oncogene; $m R N A$, messenger ribonucleic acid; $C$, control; DN, Diannexin; ICAM-1, intercellular adhesion molecule 1; PARP, poly (ADP [adenosine diphosphate]-ribose) polymerase-1.

We found that this drug improved oxygenation and alveolar fibrin deposition, which correspond to clinical features of PGD. We investigated apoptotic cell death, which is related to pulmonary IRI. ${ }^{17-19}$ Our data showed that apoptosis in the transplanted graft was suppressed by the drug, based on caspase-cleaved cytokeratin 18 and poly (ADP-ribose) polymerase-1. In addition, we demonstrated that treatment with the annexin $\mathrm{V}$ homodimer decreased proinflammatory cytokine and adhesion molecule expression in the graft, which have been shown to be associated with graft failure after clinical lung transplantation. ${ }^{26-28}$ Suppression of apoptosis and inflammation by this drug may contribute to the overall improvement of physiologic function.

Our findings further suggest that the impaired systemic fibrinolytic pathway may be ameliorated by the annexin $\mathrm{V}$ homodimer treatment, as measured by PAI-1 expression. One of the major inhibitors of the fibrinolytic system, PAI-1 has been implicated in various thrombotic disorders and is inducible by cytokines. ${ }^{29}$ A knockout-mouse model of PAI-1 improved pulmonary fibrin deposition induced by ischemia, suggesting that PAI-1 plays an important 
PAl-1

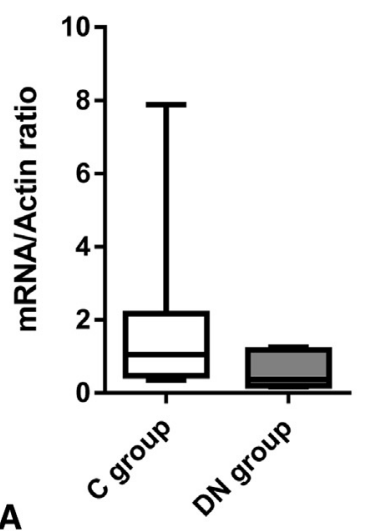

TAT complex in the graft

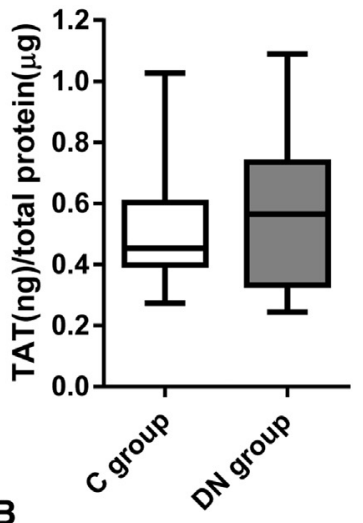

Plasma PAI-1

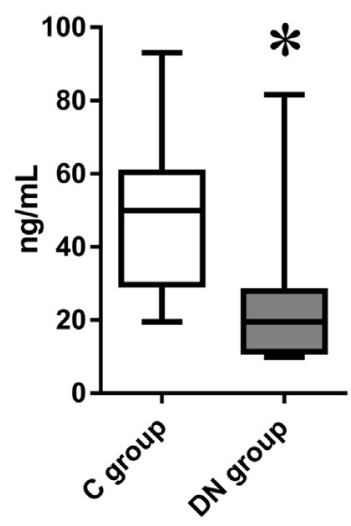

Plasma thrombin

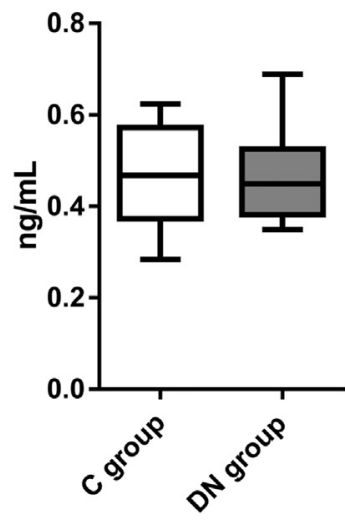

FIGURE 6. Analysis of fibrinolysis and coagulation signals. A, The mRNA of PAI-1 $(P=.054)$ in the graft and plasma protein level of PAI-1 level $(* P=.009)$ was decreased in the $\mathrm{DN}$ group. $\mathrm{B}$, The TAT complex level $(P=.84)$ in the graft, and the plasma thrombin level $(P=.67)$ were similar across study groups. PAI-1, Plasminogen activator inhibitor-1; $m R N A$, messenger RNA; $C$, control; $D N$, Diannexin; TAT, thrombin-antithrombin.

role in regulating the fibrinolytic system. ${ }^{5}$ Systemic abnormalities of fibrin turnover can occur in association with clinical acute lung injury, including acute respiratory distress syndrome and PGD. ${ }^{30,31}$ Additionally, we observed changes in the mRNA of PAI-1 in the lung graft, suggesting that systemic changes of the fibrinolytic pathway may be due to graft injury.

Alveolar fibrin deposition is one of the defining characteristics of acute lung injury. ${ }^{32}$ During tissue injury, endothelial cell dysfunction and increased vascular permeability facilitate the movement of plasma and coagulation substrates into tissue parenchyma. This annexin V homodimer has been shown to improve the vascular permeability triggered by ischemia reperfusion in rat cremaster muscle, ${ }^{12}$ similar mechanisms of which may have contributed to the improvement of alveolar pulmonary fibrin deposition in our study.

In a previous study, ${ }^{33}$ this drug was shown to bind to activated phosphatidylserine-exposing human platelets, attenuate thrombin generation in human plasma, and inhibit platelet accumulation and activation in induced thrombi in murine arterioles. However, the coagulation pathway was not significantly affected by the annexin $\mathrm{V}$ homodimer in our experimental setting.

In our study, the annexin $\mathrm{V}$ homodimer was found primarily in the reperfused graft, suggesting that phosphatidylserine exposure occurs on the reperfused endothelia, which promotes attachment of the drug. This finding additionally indicates that improvement of graft function may be directly, at least partially, associated with treatment effects of the drug in the graft, rather than with a systemic effect. In a previous study in a mouse hind-limb ischemic exercise model, the drug was localized only in the ischemic section, using radiolabeled systemic administration. ${ }^{13}$ These site specificities for ischemia-reperfused tissue would be a unique and beneficial feature of the drug, as a targeted therapy.

The efficacy of treatment with annexin $\mathrm{V}$ homodimer for IRI has been tested in a phase II clinical kidney transplantation study. ${ }^{34}$ The incidence of delayed graft function was found to be decreased, and the mean glomerular filtration rate at 29 days was improved. The result of a phase III trial is pending. These outcomes will be important in helping us determine next steps toward clinical translation of this agent.

We used this agent for both donors and recipients, based on our previous research. ${ }^{17}$ Using both a rat model and human samples, we showed that apoptosis measured by TUNEL staining is present only after reperfusion. Therefore, administering the drug to the recipient may be primarily effective. However, given that TUNEL staining is a marker of late-phase apoptosis, ${ }^{35}$ the drug could be used earlier, as it targets early-phase apoptosis. In fact, we found that the caspase pathway is already active during cold storage. ${ }^{18}$ An externalization of phosphatidylserine, which occurs in the early phase of apoptosis, ${ }^{35}$ is likely to have occurred during this time. No apparent side effects in recipients were observed. Further work is warranted to investigate the optimal timing and dosing of drug administration, including a study utilizing a large-animal model. In conclusion, an annexin $\mathrm{V}$ homodimer reduced IRI in a rat lung transplant model by reducing epithelial cell death as well as inflammation and alveolar injury.

\section{Conflict of Interest Statement}

Diannexin was provided free of charge for animal research by Astellas Pharma, Inc, (Tokyo, Japan). Authors have nothing to disclose with regard to commercial support.

You can watch a Webcast of this AATS meeting presentation by going to: http://webcast.aats.org/2015/Video/ Monday/04-27-15_6B_1748_Hashimoto.mp4. 
The authors thank Xiao-Hui Bai PhD and Pavlo Sklifasovskyy for technical assistance, and Jerome Valero and Paul Chartrand for administrative assistance.

\section{References}

1. Christie JD, Carby M, Bag R, Corris P, Hertz M, Weill D. Report of the ISHLT Working Group on Primary Lung Graft Dysfunction part II: definition. A consensus statement of the International Society for Heart and Lung Transplantation. J Heart Lung Transplant. 2005;24:1454-9.

2. Christie JD, Kotloff RM, Ahya VN, Tino G, Pochettino A, Gaughan C, et al. The effect of primary graft dysfunction on survival after lung transplantation. Am J Respir Crit Care Med. 2005;171:1312-6.

3. Christie JD, Sager JS, Kimmel SE, Ahya VN, Gaughan C, Blumenthal NP, et al. Impact of primary graft failure on outcomes following lung transplantation. Chest. 2005;127:161-5.

4. Daud SA, Yusen RD, Meyers BF, Chakinala MM, Walter MJ, Aloush AA, et al. Impact of immediate primary lung allograft dysfunction on bronchiolitis obliterans syndrome. Am J Respir Crit Care Med. 2007;175:507-13.

5. Pinsky DJ, Liao H, Lawson CA, Yan SF, Chen J, Carmeliet P, et al. Coordinated induction of plasminogen activator inhibitor-1 (PAI-1) and inhibition of plasminogen activator gene expression by hypoxia promotes pulmonary vascular fibrin deposition. J Clin Invest. 1998;102:919-28.

6. Bombeli T, Karsan A, Tait JF, Harlan JM. Apoptotic vascular endothelial cells become procoagulant. Blood. 1997;89:2429-42.

7. Pohl A, Lage H, Müller P, Pomorski T, Herrmann A. Transport of phosphatidylserine via MDR1 (multidrug resistance 1)P-glycoprotein in a human gastric carcinoma cell line. Biochem J. 2002;365:259-68.

8. Huls M, Kramers C, Levtchenko EN, Wilmer MJG, Dijkman HBPM, Kluijtmans LAJ, et al. P-glycoprotein-deficient mice have proximal tubule dysfunction but are protected against ischemic renal injury. Kidney Int. 2007; 72:1233-41.

9. Kuypers FA, Larkin SK, Emeis JJ, Allison AC. Interaction of an annexin V homodimer (Diannexin) with phosphatidylserine on cell surfaces and consequent antithrombotic activity. Thromb Haemost. 2007;97:478-86.

10. Teoh NC, Ito Y, Field J, Bethea NW, Amr D, McCuskey MK, et al. Diannexin, a novel annexin $\mathrm{V}$ homodimer, provides prolonged protection against hepatic ischemia-reperfusion injury in mice. Gastroenterology. 2007;133:632-46.

11. Hale SL, Allison AC, Kloner RA. Diannexin reduces no-reflow after reperfusion in rabbits with large ischemic myocardial risk zones. Cardiovasc Ther. 2011;29: e42-52.

12. Molski M, Groth A, Allison AC, Hendrickson M, Siemionow M. Diannexin treatment decreases ischemia-reperfusion injury at the endothelial cell level of the microvascular bed in muscle flaps. Ann Plast Surg. 2009;63:564-71.

13. Wever KE, Wagener FA, Frielink C, Boerman OC, Scheffer GJ, Allison A, et al. Diannexin protects against renal ischemia reperfusion injury and targets phosphatidylserines in ischemic tissue. PLoS One. 2011;6:e24276.

14. Shen X-D, Ke B, Zhai Y, Tsuchihashi S-I, Gao F, Duarte S, et al. Diannexin, a novel annexin $\mathrm{V}$ homodimer, protects rat liver transplants against cold ischemia-reperfusion injury. Am J Transplant. 2007;7:2463-71.

15. Cheng EY, Sharma VK, Chang C, Ding R, Allison AC, Leeser DB, et al. Diannexin decreases inflammatory cell infiltration into the islet graft, reduces $\beta$-cell apoptosis, and improves early graft function. Transplantation. 2010;90: 709-16.

16. Sack F-U, Dollner R, Reidenbach B, Koch A, Gebhard MM, Hagl S. Intravital microscopy of pulmonary microcirculation after single lung transplantation in pigs. Transplant Proc. 2006;38:737-40.

17. Fischer S, Cassivi SD, Xavier AM, Cardella JA, Cutz E, Edwards V, et al. Cell death in human lung transplantation: apoptosis induction in human lungs during ischemia and after transplantation. Ann Surg. 2000;231:424-31.

18. Quadri SM, Segall L, de Perrot M, Han B, Edwards V, Jones N, et al. Caspase inhibition improves ischemia-reperfusion injury after lung transplantation. Am J Transplant. 2005;5:292-9.

19. Fischer S, Maclean AA, Liu M, Cardella JA, Slutsky AS, Suga M, et al. Dynamic changes in apoptotic and necrotic cell death correlate with severity of ischemia-reperfusion injury in lung transplantation. Am J Respir Crit Care Med. 2000;162:1932-9.

20. Martin SJ, Reutelingsperger CP, McGahon AJ, Rader JA, van Schie RC, LaFace DM, et al. Early redistribution of plasma membrane phosphatidylserine is a general feature of apoptosis regardless of the initiating stimulus: inhibition by overexpression of Bcl-2 and Abl. J Exp Med. 1995;182:1545-56.
21. Mizuta T, Kawaguchi A, Nakahara K, Kawashima Y. Simplified rat lung transplantation using a cuff technique. J Thorac Cardiovasc Surg. 1989;97:578-81.

22. de Perrot M, Quadri SM, Imai Y, Keshavjee S. Independent ventilation of the graft and native lungs in vivo after rat lung transplantation. Ann Thorac Surg. 2005;79:2169-71.

23. Leers MP, Kölgen W, Björklund V, Bergman T, Tribbick G, Persson B, et al. Immunocytochemical detection and mapping of a cytokeratin 18 neo-epitope exposed during early apoptosis. J Pathol. 1999;187:567-72.

24. Roth GA, Krenn C, Brunner M, Moser B, Ploder M, Spittler A, et al. Elevated serum levels of epithelial cell apoptosis-specific cytokeratin 18 neoepitope M30 in critically ill patients. Shock. 2004;22:218-20.

25. Xiao H, Bai X-H, Kapus A, Lu W-Y, Mak AS, Liu M. The protein kinase C cascade regulates recruitment of matrix metalloprotease 9 to podosomes and its release and activation. Mol Cell Biol. 2010;30:5545-61.

26. Mathur A, Baz M, Staples ED, Bonnell M, Speckman JM, Hess PJ, et al. Cytokine profile after lung transplantation: correlation with allograft injury. Ann Thorac Surg. 2006;81:1844-50.

27. de Perrot M, Sekine Y, Ficher S, Waddell TK, McRae K, Liu M, et al. Interleukin8 release during early reperfusion predicts graft function in human lung transplantation. Am J Respir Crit Care Med. 2002;165:211-5.

28. Covarrubias M, Ware LB, Kawut SM, De Andrade J, Milstone A, Weinacker A, et al. Plasma intercellular adhesion molecule-1 and von Willebrand factor in primary graft dysfunction after lung transplantation. Am J Transplant. 2007;7:2573-8.

29. Sawdey MS, Loskutoff DJ. Regulation of murine type 1 plasminogen activator inhibitor gene expression in vivo. Tissue specificity and induction by lipopolysaccharide, tumor necrosis factor-alpha, and transforming growth factor-beta. J Clin Invest. 1991;88:1346-53.

30. Ware LB, Matthay MA, Parsons PE, Thompson BT, Januzzi JL, Eisner MD. Pathogenetic and prognostic significance of altered coagulation and fibrinolysis in acute lung injury/acute respiratory distress syndrome. Crit Care Med. 2007;35: 1821-8.

31. Christie JD, Robinson N, Ware LB, Plotnick M, De Andrade J, Lama V, et al. Association of protein $\mathrm{C}$ and type 1 plasminogen activator inhibitor with primary graft dysfunction. Am J Respir Crit Care Med. 2007;175:69-74.

32. Idell S. Coagulation, fibrinolysis, and fibrin deposition in acute lung injury. Crit Care Med. 2003;31:S213-20.

33. Rand ML, Wang H, Pluthero FG, Stafford AR, Ni R, Vaezzadeh N, et al. Diannexin, an annexin A5 homodimer, binds phosphatidylserine with high affinity and is a potent inhibitor of platelet-mediated events during thrombus formation. J Thromb Haemost. 2012;10:1109-19.

34. Cooper M, Kapur S, Stratta R, D’Alessandro A, Malgaonkar S, Allison A, et al. Diannexin, a novel ischemia/reperfusion therapeutic agent, reduces delayed graft function (DGF) in renal transplant recipients from marginal donors. Am J Transplant. 2010;10:S83.

35. Henson PM, Tuder RM. Apoptosis in the lung: induction, clearance and detection. Am J Physiol Lung Cell Mol Physiol. 2008;294:L601-11.

Key Words: diannexin, primary graft dysfunction, ischemia reperfusion injury, apoptosis

\section{Discussion}

Dr A. Shah (Baltimore, Md). Thank you for the opportunity to discuss this work, and I appreciate the opportunity to read your manuscript, which you provided to me. You have designed and executed a very elegant study and you are to be congratulated.

I have 3 questions. In the article, you note that the recipients received Diannexin as well. Why did you do that? And do you think there is added benefit for the recipients to have diannexin?

Dr K. Hashimoto (Toronto, Canada). The timing of the drug administration was decided based on our previous studies. In one study using a rat transplant model, and also the human lung transplant sample, we showed that 
apoptosis is activated only after reperfusion. Therefore, the drug administration for the recipient may be primarily what is important. But, apoptosis assessed in those studies was based on TUNEL, which is a late marker of apoptosis. Diannexin is targeting an early phase of apoptosis, and we know that caspase activation is initiated in the cold storage period, from a previous study we did. That is why we also add Diannexin to the donor lung.

Dr Shah. The other intriguing possibility is that you may have remote benefits of Diannexin. Diannexin has been used in renal transplantation, for example. So if there were remote effects of ischemia reperfusion to the kidneys and to the heart, it may be of potential benefit to give it to the recipients as well.

My second question is: Do you have any sense of how durable this effect is? How durable is the effect of your therapeutic treatment? Over how long a period do you think you will achieve benefit? Or is it limited to only the initial injury and perhaps an hour or so after reperfusion?

Dr Hashimoto. Since we used a 2-hour reperfusion model, we cannot answer that question. We need to do a survival model, hopefully a large-animal model, to answer that question.

Dr Shah. And my final question is: Since clinically, the actual incidence of primary graft dysfunction varies considerably, with some centers reporting rates of $10 \%$, and as you have mentioned, up to $20 \%$, would you speculate that we should use this agent on every transplant or in high-risk situations?

Dr Hashimoto. Thank you for that question. That is an important point. Since we cannot predict which patients will have PGD, I think we should use this agent for every patient. Also, we know that the apoptotic pathway is activated even before transplantation; therefore, I think it makes sense to use the agent for every patient.

Dr Dao Nguyen (Miami, Fla). I am quite perplexed about how fast apoptosis happened in your case. Do you think that you can reproduce these data using a caspase inhibitor? Do you think you can reproduce these data using a direct inhibition of apoptotic pathways using caspase inhibitors?

Dr Hashimoto. Could you repeat the question?

Dr Nguyen. Can you block apoptosis and reproduce the same data if you use caspase inhibitor instead of Diannexin?

Dr S. Keshavjee (Toronto, Canada). I can help with the answer. We did that work several years ago, so caspase inhibitors do work, and that is further down the pathway. The advantage of the phosphatidylserine blocking is that you start in the very early phase of apoptosis, because exteriorization of phosphatidylserine is a very early event in cell death, as opposed to caspase, which comes toward the end of the pathway.

Readers who found these articles interesting may also like to read the following papers found in recent and future issues of our sister publications, Seminars in Thoracic and Cardiovascular Surgery and Operative Techniques in Thoracic and Cardiovascular Surgery!

\section{Transplantation}

Original Submission: Trends in U.S. Extracorporeal Membrane Oxygenation Use and Outcomes: 2002-2012. Fenton H McCarthy. Semin Thorac Cardiovasc Surg 2015; Summer; 27(2):81-88.

Editorial Commentary: Is it Worth it to Increase the Use of Extracorporeal Membrane Oxygenation? Marco Morsolini. Semin Thorac Cardiovasc Surg 2015; Summer; 27(2):89-90.

Original Submission: Increased Procurement of Thoracic Donor Organs After Thyroid Hormone Therapy. Dimitri Novitzky. Semin Thorac Cardiovasc Surg 2015; Summer; 27(2):123-133.

Editorial Commentary: Optimizing Donor Quality Via Hormonal Therapy: An Important Strategy to Increase Successful Placement of Thoracic Organs in End-Stage Patients. Syed M. Peer. Semin Thorac Cardiovasc Surg 2015; Summer; 27(2):133-134.

State of the Art: The State of the Art in Corporeal Membrane Oxygenation. Steve K. Singh. Semin Thorac Cardiovasc Surg 2015; Spring; 27(1):17-23.

Median Sternotomy for Lung Transplantation. John Dark. Oper Tech Thorac Cardiovasc Surg 2015; Spring; 20(1):87-103.

Less Invasive Techniques for Left Ventricular Assist Device Implantation. Scott C. Silvestry. Expected Publication December 2015.

Ex Vivo Lung Perfusion. Marcelo Cypel. Oper Tech Thorac Cardiovasc Surg 2014; Winter, 19(4): 433-442.

Subcostal Approach to Replacement of a HeartMate II Device: Indications and Technique. Nader Moazami. Oper Tech Thorac Cardiovasc Surg 2014; Winter, 19(4):443-453. 